BNL-112567-2016-JA

File \# 93499

\title{
Combined Theoretical and in Situ Scattering Strategies for Optimized Discovery and Recovery of High-Pressure Phases: A Case Study of the GaN-Nb2O5 System
}

\author{
William R. Woerner, Guang-Rui Qian, Artem R. Oganov, Peter W. Stephens, \\ H. A. Naveen Dharmagunawardhane, Alexandra Sinclair, John B. Parise
}

Submitted to Inorganic Chemistry

April 4, 2016

Photon Sciences Department

Brookhaven National Laboratory

\section{U.S. Department of Energy USDOE Office of Science (SC), Basic Energy Sciences (BES) (SC-22)}

Notice: This manuscript has been authored by employees of Brookhaven Science Associates, LLC under Contract No. DE- SC0012704 with the U.S. Department of Energy. The publisher by accepting the manuscript for publication acknowledges that the United States Government retains a non-exclusive, paid-up, irrevocable, world-wide license to publish or reproduce the published form of this manuscript, or allow others to do so, for United States Government purposes. 


\section{DISCLAIMER}

This report was prepared as an account of work sponsored by an agency of the United States Government. Neither the United States Government nor any agency thereof, nor any of their employees, nor any of their contractors, subcontractors, or their employees, makes any warranty, express or implied, or assumes any legal liability or responsibility for the accuracy, completeness, or any third party's use or the results of such use of any information, apparatus, product, or process disclosed, or represents that its use would not infringe privately owned rights. Reference herein to any specific commercial product, process, or service by trade name, trademark, manufacturer, or otherwise, does not necessarily constitute or imply its endorsement, recommendation, or favoring by the United States Government or any agency thereof or its contractors or subcontractors. The views and opinions of authors expressed herein do not necessarily state or reflect those of the United States Government or any agency thereof. 


\section{Combined theoretical and in situ scattering strategies for optimized discovery and recovery of high-pressure phases: A case study of the $\mathrm{GaN}-\mathrm{Nb}_{2} \mathrm{O}_{5}$ system.}

William R. Woerner, ${ }^{\dagger}$ Guang-Rui Qian, ${ }^{\dagger}$ Artem R. Oganov, ${ }^{\dagger}$ Peter W. Stephens, ${ }^{\ddagger}$ H. A. Naveen

Dharmagunawardhane, ${ }^{\S}$ Alexandra Sinclair ${ }^{* *}$ and John B. Parise ${ }^{\dagger, * *,+t, \S \S, *}$

${ }^{\dagger}$ Department of Geosciences, Stony Brook University, Stony Brook, 11794 NY

${ }^{\ddagger}$ Department of Physics and Astronomy, Stony Brook University, Stony Brook, 11794 NY

${ }^{\S}$ Department of Materials Science and Engineering, Stony Brook University, Stony Brook, $11794 \mathrm{NY}$

${ }^{* *}$ Mineral Physics Institute, Stony Brook University, Stony Brook, 11794 NY

${ }^{+\dagger}$ Department of Chemistry, Stony Brook University, Stony Brook, 11794 NY

${ }^{\S}$ Photon Sciences, Brookhaven National Laboratory, Upton, 11934 NY 


\begin{abstract}
The application of pressure in solid-state synthesis provides a route for the creation of new and exciting materials. However, the onerous nature of high-pressure techniques limits their utility in materials discovery. The systematic search for novel oxynitrides - semiconductors for photocatalytic overall water splitting - is a representative case where quench high-pressure synthesis is useful and necessary in order to obtain target compounds. We utilize state of the art crystal structure prediction theory (USPEX) and in situ synchrotron-based X-ray scattering to speed up the discovery and optimization of novel compounds using high-pressure synthesis. Using this approach, two novel oxynitride phases were discovered in the $\mathrm{GaN}-\mathrm{Nb}_{2} \mathrm{O}_{5}$ system. The $\mathrm{Nb}_{2} \mathrm{O}_{5}(\mathrm{GaN})_{0.83}$ rutile structured phase was formed at $1 \mathrm{GPa}$ and $900^{\circ} \mathrm{C}$ and gradually transformed to a $\alpha$ structure above $2.8 \mathrm{GPa}$ and $1000^{\circ} \mathrm{C}$. The low-pressure rutile type phase was found to have a direct optical band gap $0.84 \mathrm{eV}$ of and an indirect gap of $0.51 \mathrm{eV}$.
\end{abstract}

Keywords: High-pressure Synthesis, Materials Discovery, Photocatylictic Water Splitting, Oxynitrides, Crystal Structure Prediction. 


\section{Introduction}

High-pressure (HP) synthesis is underutilized relative to exploratory solid-state chemical synthesis at ambient pressure. ${ }^{1-3}$ Despite its perceived specialist nature, "pressure tuning”4 along with serendipitous ${ }^{5}$ and theory-guided strategies, ${ }^{6}$ provide exciting avenues for the discovery of novel solid-state materials at high pressures. The specialized infrastructure that is required however, along with the slow throughput implied by the need to perform individual quench experiments to explore high-pressure and high-temperature (HPHT) phase space, conspire to limit the use of HPHT exploratory synthesis. ${ }^{3}$ Exhaustive coverage of pressure-temperature (P-T) space requires months of work using “cook-and-look” quench recovery tactics. On the other hand, recent successes in producing novel materials inspired by theory ${ }^{7-12}$ suggest collaborations employing crystal structure prediction to identify P-T conditions under which a target phases is stable, when combined with in situ observation of reactions at synchrotron and neutron sources, ${ }^{11,13}$ will facilitate and expedite HP materials discovery in the future.

The problem of crystal structure prediction is central to rational design of functional materials, and is amongst the most complex problems in solid-state inorganic chemistry. Historically computational methods have been ineffective in predicting reaction conditions and the structure of inorganic solids, and commentary on this problem has ranged from labeling it a "scandal”, ${ }^{14}$ to the somewhat more helpful suggestion that, although we cannot not as yet proceed $a b$ initio from desired property to functional material, we can proceed incrementally toward this goal. ${ }^{15}$ In the decades since such commentaries, there has been sustained and fruitful progress in computational materials discovery, which include fully non-empirical global optimization searches, such as employed by the USPEX method, ${ }^{10,16}$ and data mining techniques. ${ }^{17-19}$ These two approaches are quite complementary, especially in the case of ambient pressure synthesis. 
However, strategies relying on database searching and algorithms for substituting anion and cations into known structures are of a more limited utility when applied to potential highpressure phases as empirical knowledge is sparse and HP chemistry can be very different from that at ambient conditions. ${ }^{6,18,20}$ The $a b$ initio evolutionary algorithm embodied in the USPEX method, on the other hand, is computationally more expensive, but can be applied without depending on the availability of pre-existing empirical knowledge, and therefore is capable of predicting totally new and unexpected crystal structures and chemical compositions.

\section{Oxynitrides: Anticipated Advantages of High-Pressure Synthesis}

Oxynitride compounds have shown a wide array of properties and applications, which include pigments, dielectrics, magneto resistance, and photocatalysis. ${ }^{21}$ Oxynitrides of $\mathrm{d}^{10}$ and $\mathrm{d}^{0}$ cations have garnered significant interest in recent years due to their potential to act as overall visible light water splitting photocatalysts. ${ }^{22}$ Water splitting photocatalysts need to have conduction and valence band positions that straddle the water reduction and oxidation potentials (1.23 V), a band gap small enough to absorb in the solar spectrum, and remain chemically inert during the reaction. ${ }^{22,}{ }^{23}$ Oxynitrides are desirable as photocatalysts since they typically have narrower band gaps than respective oxides while having higher air stability and corrosion resistance as compared to nitrides. ${ }^{22,}{ }^{23}$ The most notable and efficient system being the GaN - ZnO solid solution, which has shown the ability split water under visible light irradiation with a quantum efficiency of $5.9 \% .{ }^{24}$ But as the efficiency of known photocatalysts has yet to reach levels of commercial viability, research is focused on discovering new materials.

Typically, oxynitrides are synthesized via the ammonolysis of oxides at ambient pressure; but not all oxides will react at the moderate temperatures used during ammonolysis. The application 
of HP provides a route for direct solid-state oxynitride synthesis using oxide and nitride reagents as pressure suppresses the decomposition of the nitride at high temperatures and enhance reactivity of reagents. Surprisingly, there are few examples of oxynitrides synthesized using HP methods. Examples of successful recovery experiments include LiNbO3-type $\mathrm{MnTaO}_{2} \mathrm{~N}$ at 6 $\mathrm{GPa},{ }^{25} \mathrm{BaNbO}_{2} \mathrm{~N}, \mathrm{La}_{2} \mathrm{AO}_{3} \mathrm{~N}(\mathrm{~A}=\mathrm{Al}, \mathrm{Nb}, \mathrm{Ti}, \mathrm{V})$ oxynitrides synthesized at $5 \mathrm{GPa},{ }^{26} \mathrm{RZrO}_{2} \mathrm{~N}(\mathrm{R}$ $=\mathrm{Pr}, \mathrm{Nd}, \mathrm{Sm}$ ) synthesized at 2-3 GPa, ${ }^{27}$ the spinel structured $\mathrm{Ga}_{3} \mathrm{O}_{3} \mathrm{~N}$ at pressures between 1 and $5 \mathrm{GPa},{ }^{28-31}$ the wurtzite structured $\mathrm{GaN}-\mathrm{ZnO}$ solid solution at pressures between 1.7 and 6.2 $\mathrm{GPa},{ }^{32}$ moganite-type PON prepared at $2.5 \mathrm{GPa}^{33}$ and $\delta$-PON prepared at $12.5 \mathrm{GPa}^{34}$ Highpressure synthesis is an underutilized tool in oxynitride synthesis and maybe an important complement to the accessible ammonolysis route.

\section{Using Crystal Structure Prediction to Guide Oxynitride Synthesis}

The USPEX approach has had great success in predicting HP phases that were subsequently confirmed experimentally. ${ }^{11,12,35-37}$ The current version (9.4.3) of USPEX features HP variablecomposition structure prediction that utilizes the mixing of end member chemistries, ${ }^{9}$ with the fitness function defined through the thermodynamic convex hull construction. This approach has been used, for example, to investigate the stability of new stoichiometries in the systems of Fe $\mathrm{C}, \mathrm{Fe}-\mathrm{H},{ }^{38} \mathrm{Hf}-\mathrm{C},{ }^{39} \mathrm{Na}-\mathrm{Cl},{ }^{6} \mathrm{Xe}-\mathrm{O},{ }^{40} \mathrm{Mg}-\mathrm{O},{ }^{41} \mathrm{~W}-\mathrm{B},{ }^{42,}{ }^{43}$ and $\mathrm{HfO}_{2}-\mathrm{SiO}_{2}{ }^{44}$ Experimental results confirmed the existence of the predicted $\mathrm{NaCl}_{3}$ and $\mathrm{Na}_{3} \mathrm{Cl}$ phases ${ }^{6}$ as well as $\mathrm{WB}_{3}$ and $\mathrm{WB}_{3+\mathrm{x}}$ phases. ${ }^{42}$

Accurate structure prediction using USPEX presents some challenges for HP oxynitride compounds. As nitrogen and oxygen have similar ionic size, coordination numbers, polarizability, and electronegativity, these anions can disorder across anion sites. ${ }^{21}$ While some 
oxynitride compounds exhibit partial ordering, ${ }^{45-49}$ ideally ordered oxynitrides are rarely encountered and include the only natural mineral oxynitride sinoite $\left(\mathrm{Si}_{2} \mathrm{~N}_{2} \mathrm{O}\right){ }^{50,51}$ and the TaON photocatalyst. ${ }^{52}$ UPSEX performs $0 \mathrm{~K}$ calculations only on ordered structures as occupational disorder would increase computation cost by several orders of magnitude. Including temperature and configurational entropy can result in a different structure type and a shift of the transition pressure, compared to zero Kelvin. USPEX does however provide a useful guide, identifying compositions likely to lead to thermodynamically stable materials.

Herein, we describe a method combining theoretical and experimental techniques to allow for more efficient discovery of novel materials at high-pressures. In order to ameliorate the major problems with HP-materials discovery and sample optimization, we developed new approaches that combine modern computational tools, in situ observation of reactions with X-ray diffraction while varying P-T, and structural characterization. To test these approaches, we choose to focus on the formation of novel $\mathrm{d}^{0} / \mathrm{d}^{10}$ mixed oxynitrides in the $\mathrm{GaN}-\mathrm{Nb}_{2} \mathrm{O}_{5}$ system as the system has the potential to form compounds with photocatalytic properties.

\section{Experimental}

\section{USPEX Calculations}

Using the evolutionary algorithm as implemented in USPEX $\mathrm{X}^{53-55}$ a variable-composition search was performed to generate a range of compounds with initial chemical compositions chosen at random from a mixing of $\mathrm{GaN}$ and $\mathrm{Nb}_{2} \mathrm{O}_{5}$ endmembers. This population of structures, and their compositions, then evolved with the help of variation operators (among which, transmutation and heredity are composition-changing, and lattice mutation and soft-mode mutation are composition-conservative). All the generated structures were relaxed and then ranked according 
to their fitness, with only the fittest $60 \%$ of each generation allowed to produce the next generation of structures. The underlying $a b$ initio structure relaxation and electronic structure calculations were carried out using the all electron projected augmented wave (PAW) method ${ }^{56}$ as implemented in the Vienna ab-initio simulation package (VASP) ${ }^{57}$. The Perdew-Burke-

Ernzerhof (PBE) functional was used to treat the exchange-correlation energy. ${ }^{58}$ A plane-wave kinetic cutoff energy of $600 \mathrm{eV}$ was used in addition to reciprocal space sampling with dense Monkhorst-Pack k-point meshes ${ }^{59}$ at a resolution of $2 \pi \times 0.05 \AA^{-1}$ in order to provide sufficient accuracy during enthalpy calculations.

\section{GaN Synthesis}

The GaN used for this investigation was synthesized in house via the ammonolysis of $\mathrm{Ga}_{2} \mathrm{O}_{3}$ to ensure phase purity. A 2 g sample of $\mathrm{Ga}_{2} \mathrm{O}_{3}$ (99.99\%, Sigma-Aldrich) was loaded into a quartz boat and placed in a sealed 1 inch diameter tube furnace. The atmosphere was evacuated to rough vacuum and then filled to 1 bar of pressure with ammonia gas. The $\mathrm{Ga}_{2} \mathrm{O}_{3}$ reacted with the ammonia flowing at a rate of $500 \mathrm{~mL} / \mathrm{min}$ at $950^{\circ} \mathrm{C}$ for 2 hours. The product was cooled back to room temperature under flowing ammonia and was then removed, ground for $10 \mathrm{~min}$ in an agate mortar and pestle, and then subjected to the reactions conditions described above for a second time. X-ray diffraction (XRD) of the recovered pale yellow powder revealed it consisted of nanocrystalline wurtzite-type $\mathrm{GaN}$ with no detectable $\mathrm{Ga}_{2} \mathrm{O}_{3}$.

\section{In situ HPHT XRD Investigation}

The HPHT reaction between $\mathrm{GaN}-\mathrm{Nb}_{2} \mathrm{O}_{5}$ was studied in situ at pressures and temperatures up to $3.8 \mathrm{GPa}$ and $1200^{\circ} \mathrm{C}$ using energy dispersive XRD (EDXRD) at the X17B2 beamline at the 
National Synchrotron Light Source (NSLS). A 1:1 mix of GaN and $\mathrm{Nb}_{2} \mathrm{O}_{5}$ (99.99\%, SigmaAldrich) was mechanically ground in an agate mortar and pestle for 45 minutes and loaded into a BN sleeve. The mix was stacked on top of an MgO internal pressure standard and physically separated with a layer of BN powder. The sleeve was inserted into a boron epoxy cubic DIA cell with a resistive heating graphite furnace and a $\mathrm{W}-3 \% \mathrm{Re} / \mathrm{W}-28 \%$ Re thermocouple (Figure 4). The cell was compressed using a 1000 ton multi-anvil press (BAM11) and the EDXRD patterns were collected using a white beam (14-120 keV X-rays) incident on tungsten slits to produce a $100 \mu \mathrm{m}$ x $100 \mu \mathrm{m}$ beam. The cell was first compressed to a press loading of 15 tons ( $1 \mathrm{GPa})$ and the temperature was raised to $1000^{\circ} \mathrm{C}$ with EDXRD patterns collected every $100^{\circ} \mathrm{C}$ with $300 \mathrm{~s}$ exposure after a $1000 \mathrm{~s}$ reaction time. The cell was then cooled to room temperature, followed by an increase in pressure to 25 tons. The temperature was then raised in $100^{\circ} \mathrm{C}$ increments to $1200^{\circ} \mathrm{C}$ with the same EDXRD data collection strategy described above employed at the end of each increment with the process again repeated at 35 tons.

\section{HPHT Piston Cylinder Quench Experiments}

HPHT reactions between $\mathrm{GaN}$ and $\mathrm{Nb}_{2} \mathrm{O}_{5}$ were carried out ex situ using a piston cylinder apparatus at P-T points selected according to the phase stability fields determined from the in situ EDXRD results. For the $1 \mathrm{GPa}$ experiment, a $19 \mathrm{~mm}$ (0.75 inch) diameter piston cylinder setup was used to maximize the sample volume. Approximately $1 \mathrm{~g}$ of the $\mathrm{GaN}-\mathrm{Nb}_{2} \mathrm{O}_{5}$ mix was loaded in a graphite furnace and encapsulated within the cylinder with two BN disks. The sample was centered in the furnace using two pyrophyllite plugs that were previously fired at $1000^{\circ} \mathrm{C}$ for 20 minutes. The temperature was monitored with a $\mathrm{Pt} / \mathrm{Pt}_{90}-\mathrm{Rh}_{10}$ thermocouple pressed against the BN disk just above the sample in the talc cell assembly (Figure 1). The entire assembly was cold 
compressed to the desired pressure and ramped up to temperature while holding the pressure constant. The experiments were left to react for 1 hour and then quenched isobarically. For the 3 GPa quench experiment, a $12.7 \mathrm{~mm}(0.5 \mathrm{inch})$ diameter piston cylinder assembly was used, as the $19 \mathrm{~mm}$ diameter assembly could not reach such high pressures. The $12.7 \mathrm{~mm}$ diameter cell assembly is a scaled down version of what is shown in Figure 4, with a substitution of alumina for pyrophyllite plugs. However, only about 50-100 mg of the mix can be loaded in such an assembly. After decompression, the sample pellets were removed from the assembly and physically cleaned to remove any contamination from the cell assembly before grinding.
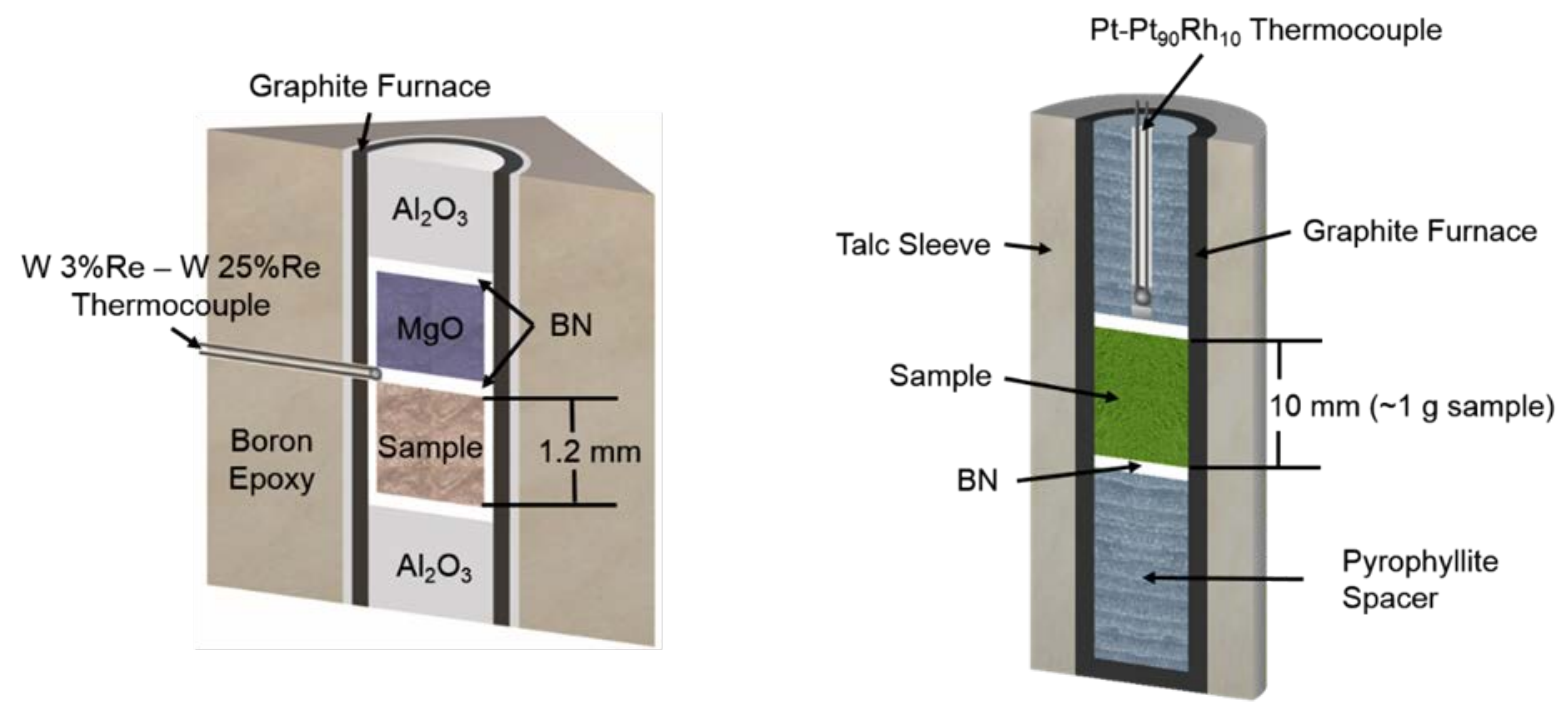

Figure 1. Cross section of the cubic cell assembly (left) used at the X17B2 beamline at NSLS and the $19 \mathrm{~mm}$ diameter piston cylinder cell assembly (right). The cubic assembly measures 6.35 $\mathrm{mm}$ on each side and the overall length of the piston cylinder assembly is $4.45 \mathrm{~cm}$. 


\section{Analytical Methods}

The quenched samples were initially characterized with powder XRD using a Rigaku Ultima IV $(\mathrm{CuK} \alpha)$ with a D/Tex linear position sensitive detector in Bragg-Brentano geometry. After phase identification and comparison with in situ EDXRD patterns, the crystalline powders were structurally characterized using synchrotron high resolution XRD and the 1 GPa sample was additionally investigated with time-of-flight (TOF) powder neutron diffraction. High-resolution powder XRD investigations were carried out at the 11-BM beamline at the Advanced Photon Source. The high-resolution XRD patterns were collected with a wavelength of $0.41383(1) \AA$ at room temperature while the samples were spun on a goniometer in a kapton ${ }^{\circledR}$ capillary. The patterns were collected over an angular range of $0.8^{\circ} \leq 2 \theta \leq 49.99^{\circ}$ with a step size of $0.001^{\circ}$. The TOF powder neutron diffraction experiment was conducted using the POWGEN instrument (BL-11) at the Spallation Neutron Source. Approximately $1 \mathrm{~g}$ of sample was loaded into a $6 \mathrm{~mm}$ vanadium can and data were collected using frames 1 and 5 (chopper wavelength centered at 0.533 and $3.731 \AA$ respectively) giving access to a range of $0.25 \AA \leq \mathrm{d} \leq 6 \AA$. Diffuse reflectance spectra were collected using an ASD Fieldspec3 Mac UV-VIS-NIR spectrometer with an Ocean Optics HL-2000-HP tungsten halogen light source. The compositional analysis with inert gas fusion (for $\mathrm{O}$ and $\mathrm{N}$ ) and direct current plasma emission spectroscopy (for $\mathrm{Ga}$ and $\mathrm{Nb}$ ) was carried out by Luvak inc., Boylston, MA.

\section{Results}

\section{$\mathrm{GaN}-\mathrm{Nb}_{2} \mathrm{O}_{5}$ USPEX Calculations}

Variable-composition structure prediction calculations in the $(\mathrm{GaN})_{\mathrm{x}}-\left(\mathrm{Nb}_{2} \mathrm{O}_{5}\right)_{\mathrm{y}}$ system were performed at 0 and $20 \mathrm{GPa}$ to evaluate the stability of oxynitride compounds encountered. While 
the commercial zone of high-pressure is most desirable $(<6 \mathrm{GPa}$ ) for potential in scale-up production, the calculations need to be conducted at a significant overpressure to compensate for the $0 \mathrm{~K}$ temperature of the calculations. At $0 \mathrm{GPa}$, the calculations indicate all of the predicted compounds are unstable and decomposition into the endmembers wurtzite $\mathrm{GaN}$ and $\mathrm{R}-\mathrm{Nb}_{2} \mathrm{O}_{5}$ is energetically favored (Figure 2 - left). However, calculations at $20 \mathrm{GPa}$ indicate a stable oxynitride with a composition of $\mathrm{GaNb}_{2} \mathrm{O}_{5} \mathrm{~N}$ as the enthalpy of formation is lower than that of the end members wurtzite $\mathrm{GaN}$ and $\mathrm{Z}-\mathrm{Nb}_{2} \mathrm{O}_{5}$ (Figure 2 - right). The structure of the predicted ordered $\mathrm{GaNb}_{2} \mathrm{O}_{5} \mathrm{~N}$ phase is shown in Figure 3. The $20 \mathrm{GPa}$ calculations indicate a high probability of a reaction occurring at HP, although the predicted structure did not match that of either of the oxynitride phases found in the HPHT experiments, described below.
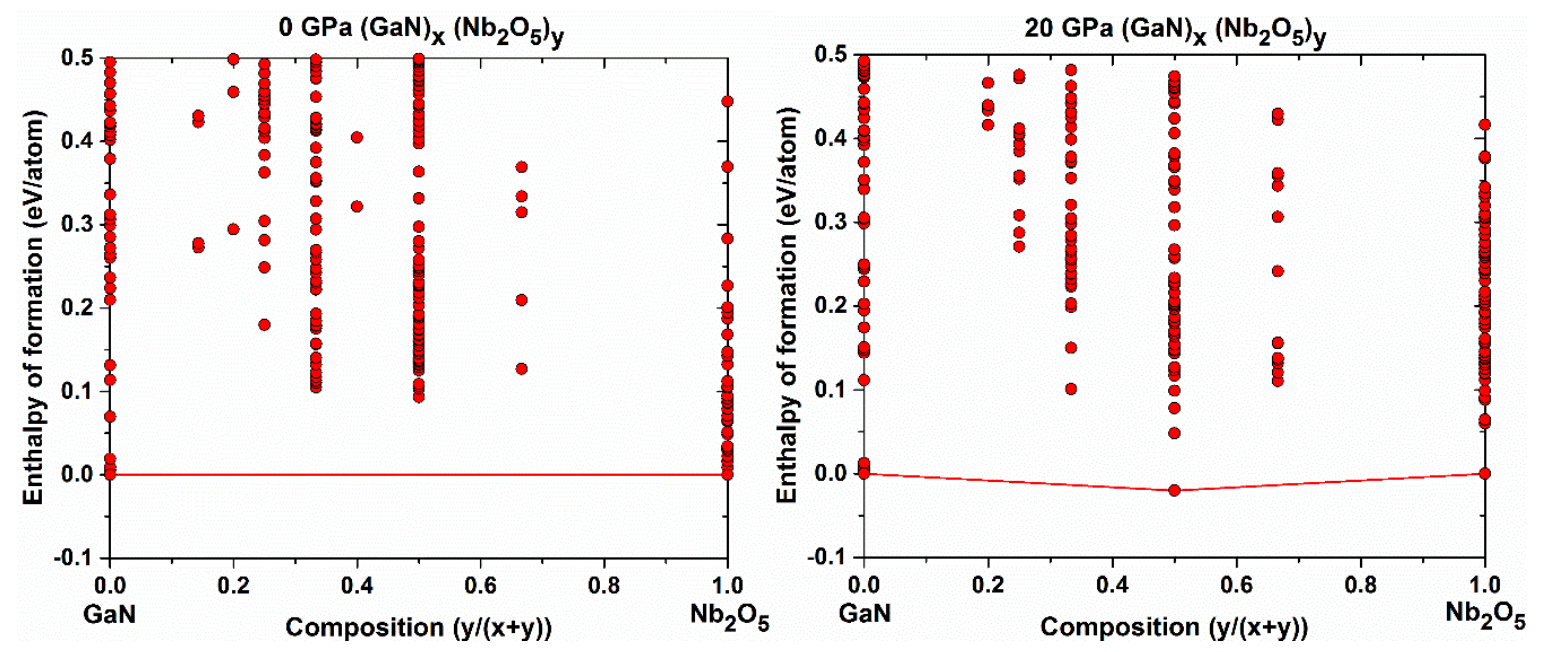

Figure 2. Predicted enthalpies of formation for $\mathrm{GaN}-\mathrm{Nb}_{2} \mathrm{O}_{5}$ compounds at ambient pressure (left) and $20 \mathrm{GPa}$ (right). The circles represent individual structures and are plotted as compositions versus enthalpies of formation. 

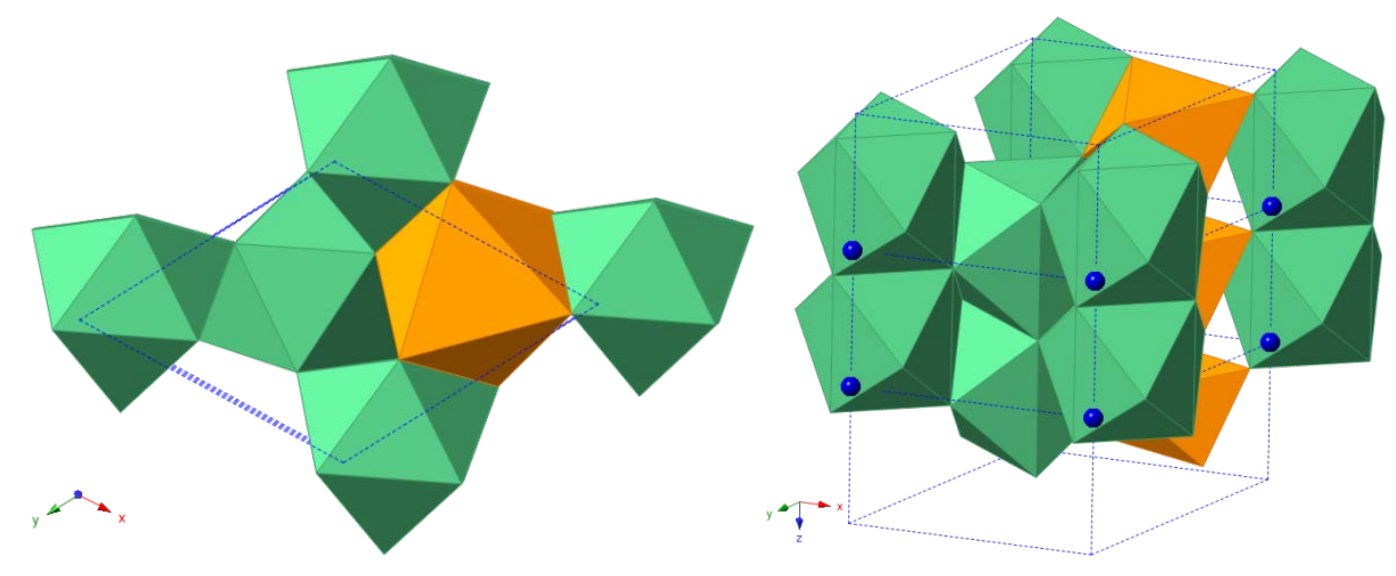

Figure 3. Lowest energy $\mathrm{GaNb}_{2} \mathrm{O}_{5} \mathrm{~N}$ structure predicted to be stable at $20 \mathrm{GPa}$. Gallium (orange) is coordinated by 6 oxygen atoms in a distorted octahedra while niobium (green) is coordinated by 7 oxygen atoms and 2 nitrogen atoms in a tricapped trigonal prism geometry. Unit cell is outlined with dashed blue line.

\section{In situ HPHT EDXRD}

The EDXRD results of the in situ HPHT reaction study conducted at the X17B2 beamline at the National Synchrotron Light Source are summarized in Figures 4, 5, and 6. At approximately $1 \mathrm{GPa}$, we observe the onset of a reaction between $\mathrm{GaN}$ and $\mathrm{Nb}_{2} \mathrm{O}_{5}$ at $800^{\circ} \mathrm{C}$ as noted by a complete restructuring of the XRD pattern and a diminishment of the (101) GaN reflection (Figure 4); the reaction is complete by $1000^{\circ} \mathrm{C}$. The new $\mathrm{Ga}-\mathrm{Nb}$ oxynitride observed at $\sim 1 \mathrm{GPa}$ has major reflections in the EDXRD patterns at approximately 1.74 (211) and $1.64 \AA$ (220), consistent with a rutile type $\left(\mathrm{TiO}_{2}\right)$ structure (described below). At $\sim 2.8 \mathrm{GPa}$ and $900^{\circ} \mathrm{C}$, the intensity of peaks attributed to the rutile type phase begin to diminish as new reflections belonging to a $\alpha-\mathrm{PbO}_{2}$ type structure appear, indicative of a phase transition (Figure 5). Moreover, as the sample temperature is increased past $800^{\circ} \mathrm{C}$ at $3-4 \mathrm{GPa}$, the phase transition 
continues with an increasing intensity of the $\alpha-\mathrm{PbO}_{2}$ reflections but without the complete disappearance of reflections attributable to the rutile type phase (Figure 6).

The EDXRD patterns of the in situ HPHT investigation revealed two novel oxynitride phases exist in the $\mathrm{GaN}-\mathrm{Nb}_{2} \mathrm{O}_{5}$ system below $3.8 \mathrm{GPa}$ and $1200^{\circ} \mathrm{C}$. The EDXRD patterns indicate the optimal conditions for the quench synthesis of the rutile and $\alpha-\mathrm{PbO}_{2}$ type phases are $1 \mathrm{GPa}$ and $1000^{\circ} \mathrm{C}$, and $3.8 \mathrm{GPa}$ and $1200^{\circ} \mathrm{C}$, respectively. As the piston-cylinder apparatus is limited to $\mathrm{P} \leq$ $3 \mathrm{GPa}$, the quench experiment targeting the $\alpha-\mathrm{PbO}_{2}$ phase was conducted at $3 \mathrm{GPa}$ and $1200^{\circ} \mathrm{C}$ in order to maximize the amount of this phase in the sample.

The in situ studies of the $\mathrm{GaN}-\mathrm{Nb}_{2} \mathrm{O}_{5}$ reaction mapped phase stability in P-T space and provided the optimal reaction temperatures for synthesis, thereby limiting the number of quench experiments required to recover the high-pressure phases to two. This represents a considerably higher success rate than could be realized from the use of single P-T quench exploratory synthesis. Multi-anvil press assemblies at user facilities offer fast and extensive evaluation of reactions at industrially viable pressures and temperatures. Cell assemblies can also be made to house two different reactions with a pressure calibrant to speed up P-T exploration even further. With this experimental setup, two chemical systems can be evaluated up to modest pressures and temperatures ( $\sim 5 \mathrm{GPa}$ and $1500^{\circ} \mathrm{C}$ ) in a period of 24 hours. The alternative process of conducting several quench-recovery experiments followed by the characterization of recovered phases to map P-T space could require weeks or months of work. 


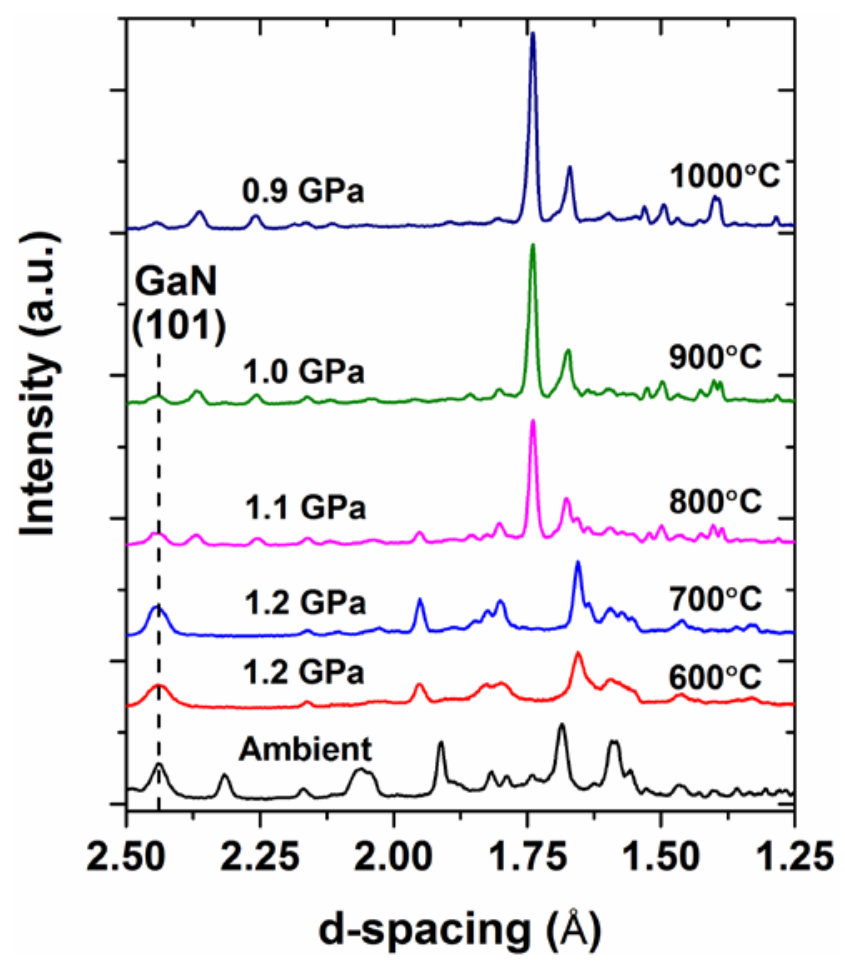

Figure 4. In situ EDXRD patterns of a 1:1 mixture of $\mathrm{GaN}$ and $\mathrm{Nb}_{2} \mathrm{O}_{5}$ at a constant press loading of 15 tons. The EDXRD pattern of the initial $\mathrm{GaN}: \mathrm{Nb}_{2} \mathrm{O}_{5}$ mixture at ambient pressure and temperature is at the bottom of the figure in black and contains peaks attributed to only wurtzitetype $\mathrm{GaN}$ and monoclinic $\mathrm{Nb}_{2} \mathrm{O}_{5}$. Upon pressing the sample to $1.2 \mathrm{GPa}$ and heating to $600^{\circ} \mathrm{C}$ and $700^{\circ} \mathrm{C}$, the $\mathrm{Nb}_{2} \mathrm{O}_{5}$ underwent a phase transformation to the orthorhombic phase but did not react. At $\sim 800^{\circ} \mathrm{C}$ however, the $\mathrm{XRD}$ pattern undergoes a drastic change indicative of a reaction, highlighted by the decrease in intensity for the major GaN (101) refection as the rutile structured oxynitride phase forms. The reaction is essentially complete by $1000^{\circ} \mathrm{C}$, with only minor GaN left unreacted. 


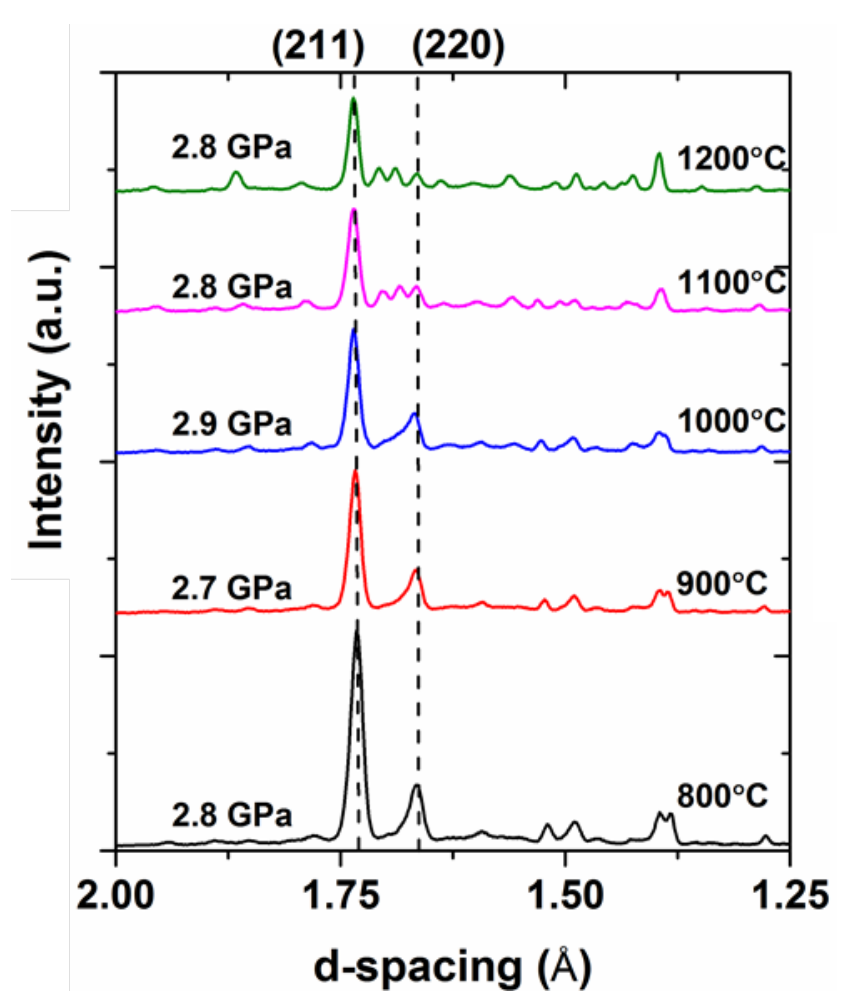

Figure 5. In situ EDXRD patterns of $\mathrm{GaN}-\mathrm{Nb}_{2} \mathrm{O}_{5}$ reaction at a constant press loading of 25 tons. The rutile oxynitride phase remains the only Ga-Nb oxynitride phase in the pattern as the sample is heated to $800^{\circ} \mathrm{C}$. At $900^{\circ} \mathrm{C}$, the intensity of the rutile type (211) and (220) reflections begin decreasing and new peaks in the pattern are apparent by $1200^{\circ} \mathrm{C}$, belonging to the new $\alpha$ $\mathrm{PbO}_{2}$ type oxynitride phase. 


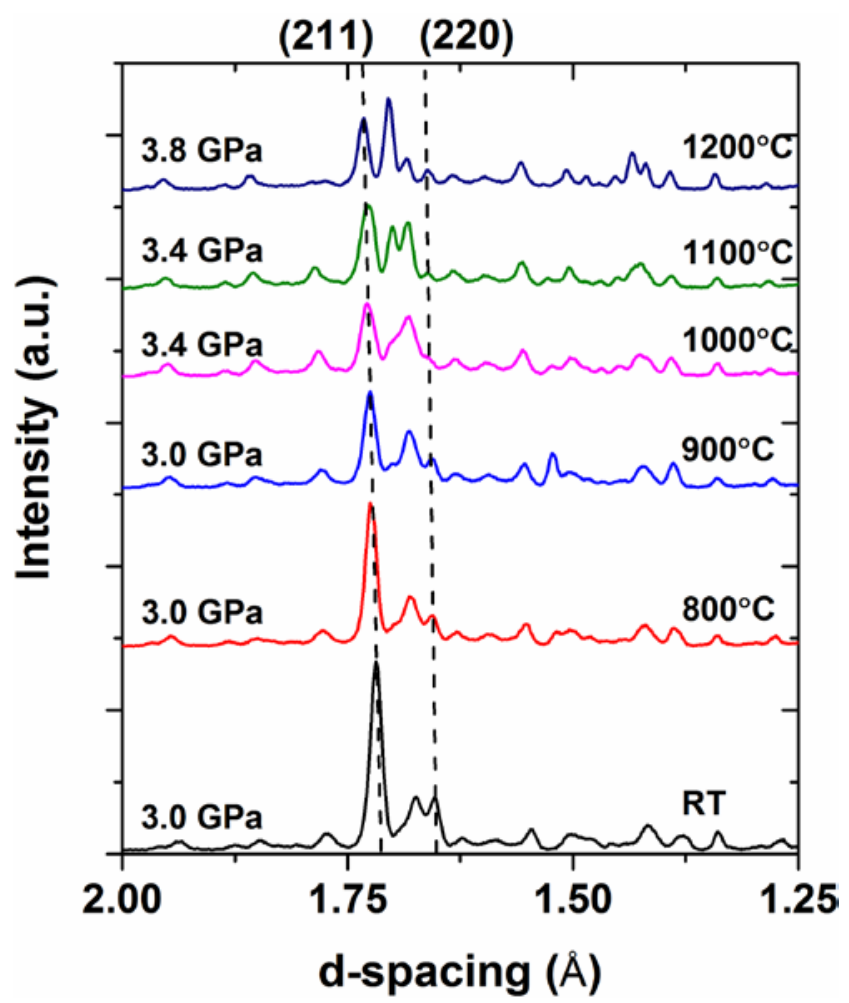

Figure 6. In situ EDXRD patterns of $\mathrm{GaN}-\mathrm{Nb}_{2} \mathrm{O}_{5}$ reaction at a constant press loading of 35 tons. Following the trend at 25 tons, as the temperature is increased, we see a decrease in the intensity of the rutile type phase (211) and (220) reflection and the new peaks belonging to the $\alpha$ $\mathrm{PbO}_{2}$ type phase increase in intensity through $1200^{\circ} \mathrm{C}$.

\section{Structural Characterization}

\section{$1 \mathrm{GPa}-1000^{\circ} \mathrm{C}$}

The product of the $1 \mathrm{GPa}-1000^{\circ} \mathrm{C}$ quench experiment was evaluated with both highresolution XRD and TOF powder neutron diffraction. After known phases were identified, the new oxynitride phase in the XRD pattern was indexed, its crystal structure solved, and a Rietveld refinement conducted with the program TOPAS (v4.1, Bruker AXS). The major phase is a new oxynitride found to have the rutile structure with minor $\mathrm{GaN}, \mathrm{GaNbO}_{4}$, and $T-\mathrm{Nb}_{2} \mathrm{O}_{5}$ also 
identified in the sample (Figure 7). The $\mathrm{GaNbO}_{4}$ phase forms due to a $\mathrm{Ga}_{2} \mathrm{O}_{3}$ impurity in the reactant GaN powder (Figure S1). Because of the large X-ray scattering contrast between $\mathrm{Nb}^{5+}$ and $\mathrm{Ga}^{3+}$, the occupancies of $\mathrm{Nb}^{5+}$ and $\mathrm{Ga}^{3+}$ on the single metal site were refined, with the constraint that the total occupancy of the site is 1.0.

The X-ray scattering contrast between $\mathrm{O}^{2-}$ and $\mathrm{N}^{3-}$ on the other hand is small, and so neutron diffraction data were collected on the same sample as the neutron scattering contrast is high $\left(b_{\mathrm{O}}\right.$ $=5.803 \mathrm{fm} ; b_{\mathrm{N}}=9.36 \mathrm{fm}$ ) and can resolve the O/N occupancy and any possible ordering on the anion site. A structure model was refined using two TOF frames and the GSAS/EXPGUI

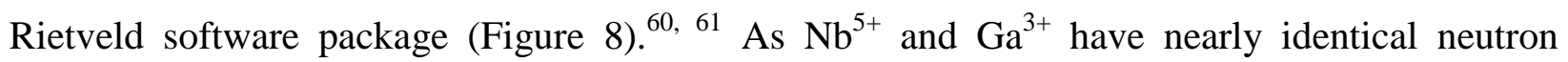
scattering lengths $\left(b_{\mathrm{Nb}}=7.054 \mathrm{fm} ; b_{\mathrm{Ga}}=7.288 \mathrm{fm}\right.$ ), the rutile type metal site was fixed to the ratio determined from the XRD refinement. The occupancy of $\mathrm{O}^{2-}$ and $\mathrm{N}^{3-}$ on the anion site was allowed to freely refine (constrained to add to 1 ). Using the refined occupancies on both the cation and anion sites, the chemical formula for the rutile related phase is $\mathrm{Nb}_{1.41} \mathrm{Ga}_{0.58} \mathrm{O}_{3.41} \mathrm{~N}_{0.59}$. To satisfy charge balance, this formula implies some reduction of $\mathrm{Nb}^{5+}$ or the existence of vacancies in the site occupied by $\mathrm{Nb} / \mathrm{Ga}$, or both. In the case of $\mathrm{Nb}^{5+}$ reduction, the composition may then nominally be represented as $\left(\mathrm{Nb}_{2} \mathrm{O}_{5}\right)_{0.84}:\left(\mathrm{NbO}_{2}\right)_{0.32}:(\mathrm{GaN})_{0.82}$. No additional, superstructure peaks could be detected in either data sets indicating that both the anion and cation sites where indeed disordered.

The average composition of the sample synthesized at $1 \mathrm{GPa}$, calculated from Rietveld refinements and taking into account the phases which constitute it (Figure 7) is $\mathrm{Nb}_{1.28} \mathrm{Ga}_{0.72} \mathrm{O}_{3.16} \mathrm{~N}_{0.67}$. Bulk chemical analysis yielded an average overall composition of $\mathrm{Nb}_{1.26} \mathrm{Ga}_{0.72} \mathrm{O}_{3.56} \mathrm{~N}_{0.44}$ (see supporting information) agreeing very well with $\mathrm{Ga}$ and $\mathrm{Nb}$ content calculated from refinements, though $\mathrm{N}$ and $\mathrm{O}$ contents were slightly different. We consider that 
given the multi-phase nature of the sample, the phase specific nature of the Rietveld refinement, and the scattering contrast between nitrogen and oxygen in particular, that the composition obtained from the neutron refinement (Tables 1 - 3) gives an accurate measure of the nitrogen content of the rutile-related phase.

The refinement details and crystallographic data for the rutile relate phase is given in Table 1 (X-ray) and Table 2 (TOF neutron). The content of the $\mathrm{Ga}^{3+}$ and $\mathrm{N}^{3-}$ show excellent agreement between the two independent X-ray and neutron refinements indicating GaN directly reacts with $\mathrm{Nb}_{2} \mathrm{O}_{5}$ and the $\mathrm{Ga}_{2} \mathrm{O}_{3}$ component is ignored. A joint X-ray/neutron refinement was attempted using GSAS/EXPGUI but the X-ray profile parameters could not model the peak shape well enough to carry out a stable refinement. Structural details and selected bond lengths of both phases can be found in Table 3 and 4, respectively. 


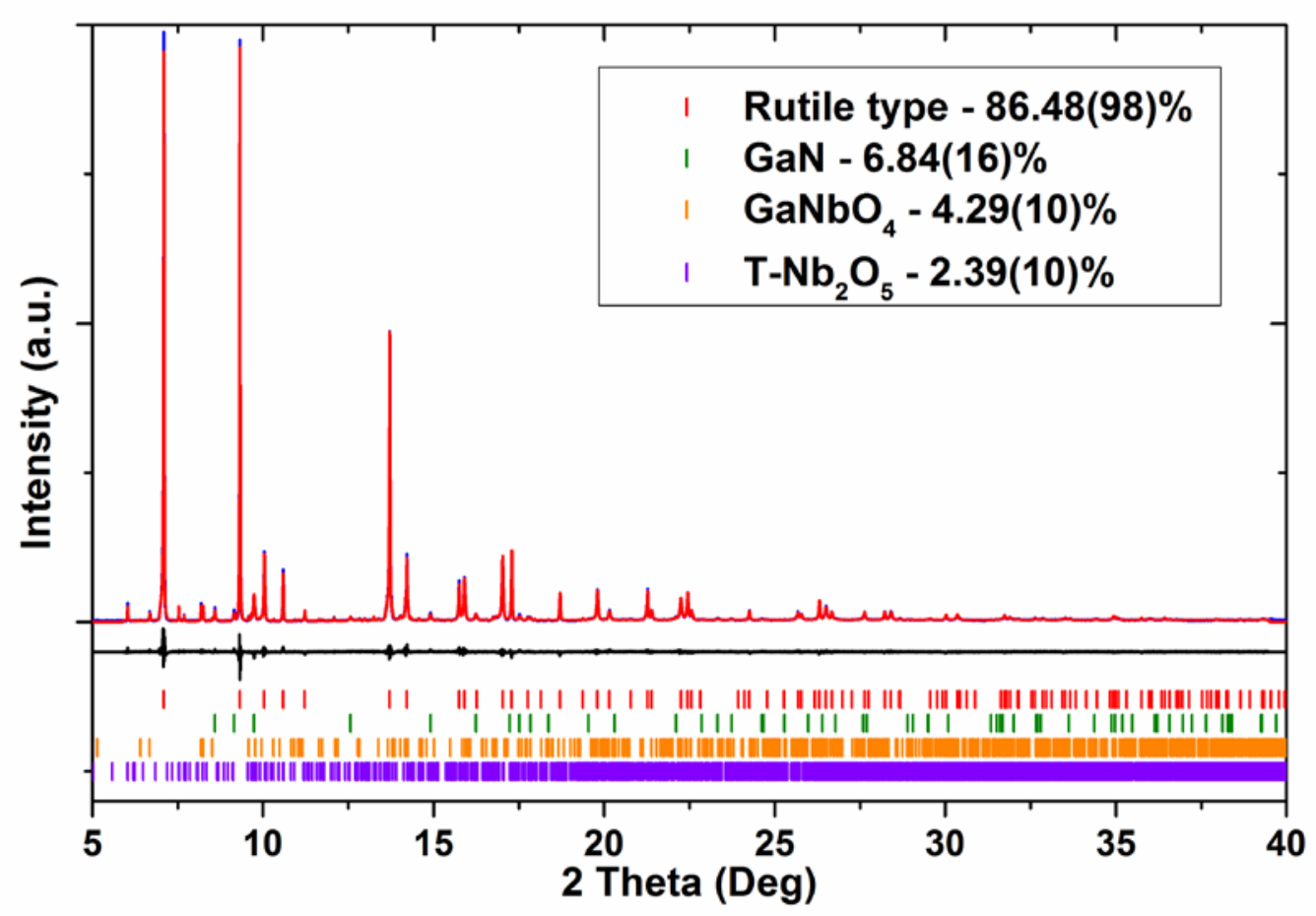

Figure 7. XRD Rietveld refinement result of the $1 \mathrm{GPa}-1000^{\circ} \mathrm{C}$ The collected pattern is shown in blue, the calculated pattern in red, and the difference in black. The tick marks show the positions of reflections of the respective phases; starting from top red markers represent positions for reflections from rutile type phase, green for $\mathrm{GaN}$, brown for $\mathrm{GaNbO}_{4}$ and purple for $\mathrm{TONb}_{2} \mathrm{O}_{5}$. Phase fractions are shown in weight percentages. 


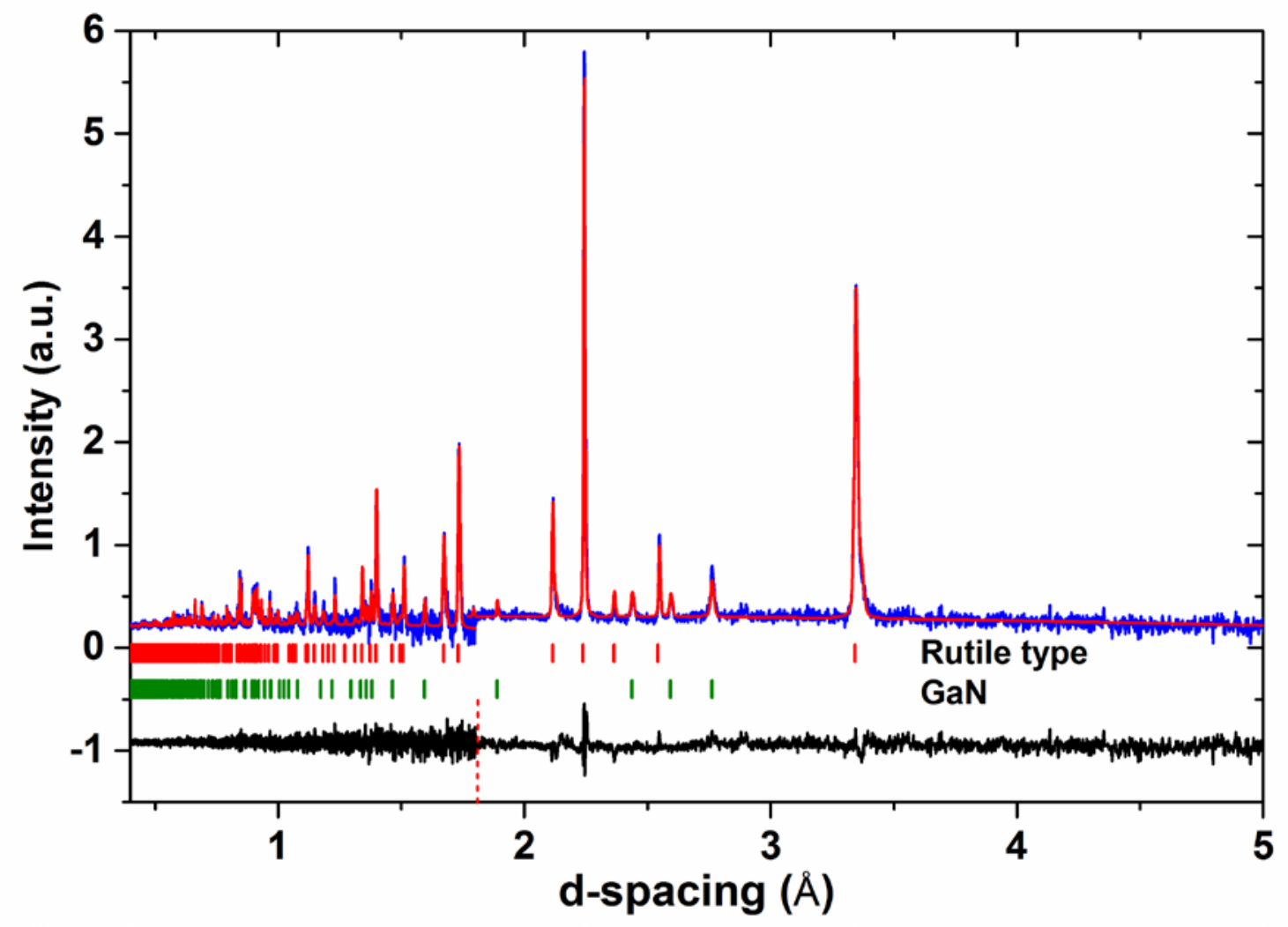

Figure 8. TOF powder neutron Rietveld refinement result of the $1 \mathrm{GPa}-1000^{\circ} \mathrm{C}$ synthesis. The patterns from both frames 1 (left) and 5 (right) are shown and are separated by the red dashed line in the difference pattern. The collected pattern is shown in blue, the calculated pattern in red, and the difference in black. The tick marks show the positions of reflections of the respective phases. The $\mathrm{GaNbO}_{4}$ and $\mathrm{T}-\mathrm{Nb}_{2} \mathrm{O}_{5}$ reflections were too weak to be incorporated into the refinement. 


\section{$3 \mathrm{GPa}-1200^{\circ} \mathrm{C}$}

The synthesis at $3 \mathrm{GPa}-1200^{\circ} \mathrm{C}$ yielded approximately $50 \mathrm{mg}$ of sample used to collect a high-resolution powder XRD pattern. A Rietveld refinement using TOPAS revealed three phases to be present in sample - major rutile type, and minor $\alpha-\mathrm{PbO}_{2}$ type in addition to GaN (Figure 9). The oxide phases of $\mathrm{GaNbO}_{4}$ and $\mathrm{Nb}_{2} \mathrm{O}_{5}$ that were present in the lower pressure $(1 \mathrm{GPa})$ sample are notably absent and have participated in the reaction at $3 \mathrm{GPa}$. The rutile type phase in the sample has a large asymmetric peak shape likely due to chemical inhomogeneity during the slow phase transition to $\alpha-\mathrm{PbO}_{2}$ type phase. The asymmetric peak shape of the rutile type phase was modeled as eleven rutile phases, with a constrained distribution of tetragonal lattice parameters (Figure 9 inset), the scale factor for each phase was freely refined. See SI for more information on the structure model. While the constrained multiphase approach did model the rutile type intensities well, the cation occupancy was globally set for the distribution of phases and allowed to refine. The occupancies of the individual rutile type phases cannot be refined due to the reflection overlap, so the distribution of chemistries and the actual occupancy of $\mathrm{Ga}$ and $\mathrm{Nb}$ in these phases cannot be accurately determined. With that caveat, trial refinements hinted at a difference between the rutile-type phases recovered in the $1 \mathrm{GPa}$ and $3 \mathrm{GPa}$ samples. For example, while the $1 \mathrm{GPa}$ sample contains a single rutile-related phase with Nb-occupancy of 0.7 (Table 3), the fits of the distribution of rutiles in the 3 GPa sample suggested the same Nb occupancy of $\sim 0.55$ across the whole distribution. This suggests that the inhomogeneity is predominantly in the $\mathrm{O} / \mathrm{N}$ site and that this is changing as the lower pressure rutile phase gradually transforms to the high pressure phase. 
The chemistry of the $\alpha-\mathrm{PbO}_{2}$ type phase was set to that of the $1 \mathrm{GPa}$ rutile phase, and was not refined, because when the cation occupancy was left to freely refine, it was unstable and would converge at unrealistic ratios of $\mathrm{Ga}$ and $\mathrm{Nb}$ with no improvement to the refinement. The refinement and crystallographic details of the $\alpha-\mathrm{PbO}_{2}$ type phase are show in Table 1 . The crystal structure of the rutile type phase is shown in comparison to the $\alpha-\mathrm{PbO}_{2}$ type in Figure 10 .

The $\mathrm{GaN}-\mathrm{Nb}_{2} \mathrm{O}_{5}$ system presents a worst-case scenario for evaluating crystal structure prediction theory as a guide for synthetic efforts. Apart from possible vacancies and multivalence of $\mathrm{Nb}$, both anion and cation sites have the potential for considerable disorder. In oxides at 6-fold coordination, $\mathrm{Ga}^{3+}$ and $\mathrm{Nb}^{5+}$ have nearly identical ionic radii $\left(\mathrm{Ga}^{3+}=0.62\right.$ and $\left.\mathrm{Nb}^{5+}=0.64 \AA\right) .{ }^{62}$ In retrospect, it is not surprising the predicted structure does not match the experimental results due to the high probability that configurational entropy would lower the Gibbs free energy of formation of new phases, with occupational disorder being possible between $\mathrm{Ga}^{3+}$ and $\mathrm{Nb}^{5+}$ as well as $\mathrm{N}^{3-}$ and $\mathrm{O}^{2-}$, which the current version of USPEX does not take into account. The USPEX calculations are useful however in guiding us to attempt a 1:1 mix of GaN and $\mathrm{Nb}_{2} \mathrm{O}_{5}$ and in correctly predicting this composition is only synthesizable at high pressures. 


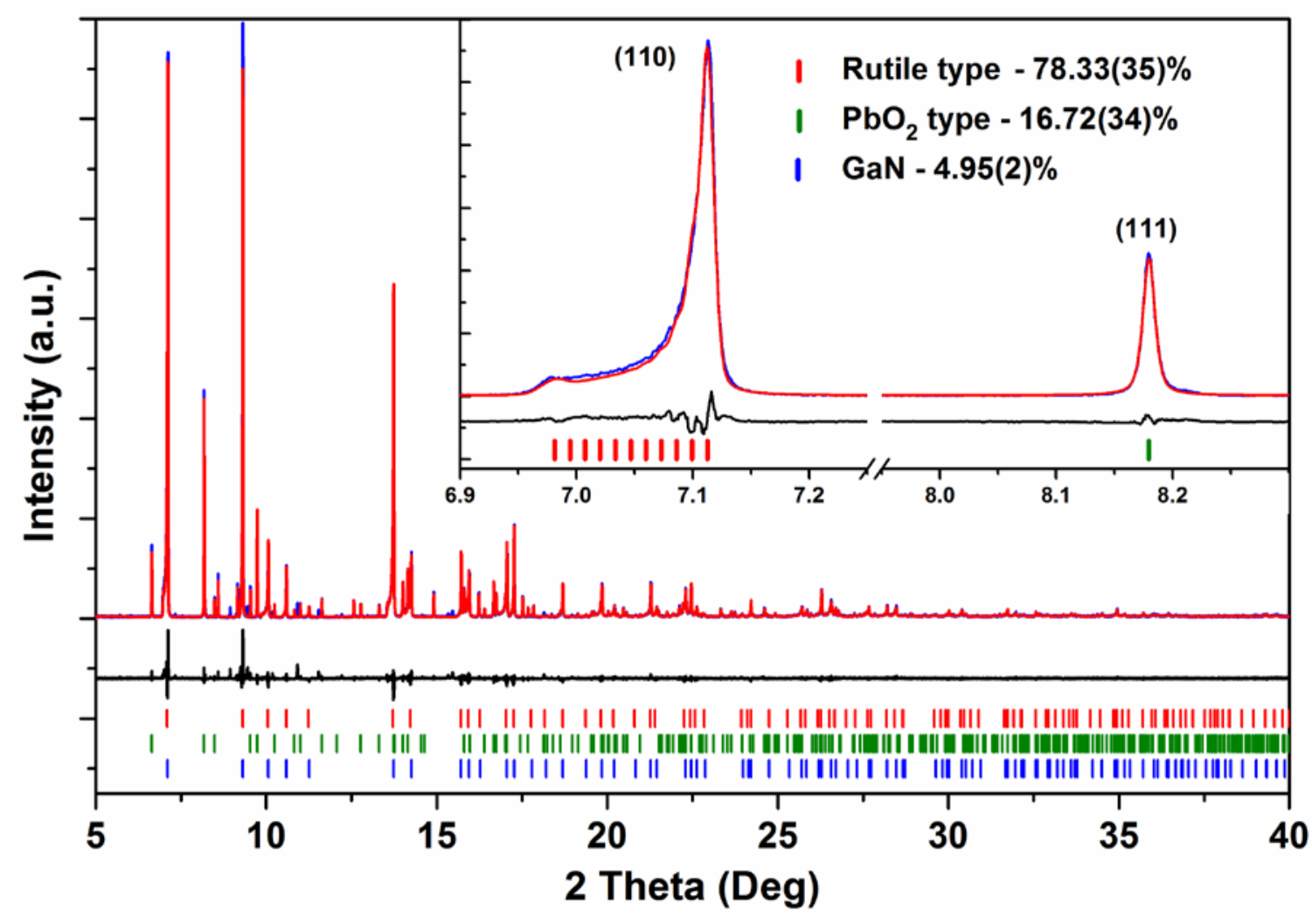

Figure 9. XRD Rietveld refinement result of a sample synthesized at $3 \mathrm{GPa}-1200^{\circ} \mathrm{C}$ and containing contributions to the diffraction pattern from rutile type phase, $\alpha-\mathrm{PbO}_{2}$ type phase and unreacted GaN. The collected pattern is shown in blue, the calculated pattern in red, and the difference in black. The vertical tick marks below the difference pattern show the positions of reflections of the respective phases; starting from the top, red markers represent positions for reflections from rutile type phase, green for $\alpha-\mathrm{PbO}_{2}$ type phase and blue for GaN.. The inset compares the largest reflection of the rutile type (110) with that of the $\alpha-\mathrm{PbO}_{2}$ type (111). For the (110) reflection there are eleven tickmarks belonging to distribution of phases used to model variable composition of the rutile-type phase. 
Table 1. Summary of the results of Rietveld refinements using X-ray data

\begin{tabular}{|c|c|c|}
\hline & Rutile type & $\alpha-\mathrm{PbO}_{2}$ type \\
\hline Pressure & $1 \mathrm{GPa}$ & $3 \mathrm{GPa}$ \\
\hline Temperature & $1000^{\circ} \mathrm{C}$ & $1200^{\circ} \mathrm{C}$ \\
\hline Space Group & $\mathrm{P} 4_{2} / \mathrm{mnm}$ & Pbcn \\
\hline$a(\AA)$ & 4.72939(3) & $4.63629(3)$ \\
\hline$b(\AA)$ & 4.72939(3) & $5.59467(4)$ \\
\hline$c(\AA)$ & $3.02110(2)$ & 4.97802(3) \\
\hline Volume $\left(\AA^{3}\right)$ & $67.573(1)$ & 129.122(1) \\
\hline$R p$ & 0.9031 & 0.9468 \\
\hline$w R p$ & 0.1188 & 0.1379 \\
\hline$\chi^{2}$ & 1.628 & 1.513 \\
\hline
\end{tabular}


Table 2. Neutron Rietveld refinement results for rutile type phase, data collected from sample synthesized by a quench experiment recovered from $1 \mathrm{GPa}$.

\begin{tabular}{ll}
\hline Pressure & $1 \mathrm{GPa}$ \\
Temperature & $1000^{\circ} \mathrm{C}$ \\
Space Group & $\mathrm{P} 4{ }_{2} / \mathrm{mnm}$ \\
$a(\AA)$ & $4.7282(2)$ \\
$b(\AA)$ & $4.7282(2)$ \\
$c(\AA)$ & $3.0137(1)$ \\
Volume $\left(\AA^{3}\right)$ & $67.373(5)$ \\
Frame $1 R_{p}$ & 0.1167 \\
Frame $1 w R_{p}$ & 0.0799 \\
Frame $5 R_{p}$ & 0.1366 \\
Frame $5 w R_{p}$ & 0.1062 \\
$\chi 2$ & 1.621 \\
\hline
\end{tabular}


Table 3. Structure details determined refined models using neutron and X-ray.

\begin{tabular}{lllll}
\hline Atom & $\mathbf{x}$ & $\mathbf{y}$ & $\mathbf{z}$ & $\mathbf{U}_{\text {iso }} \mathrm{X} 10^{2}\left(\AA^{2}\right)$ \\
Rutile-Type (Neutron) & & & & \\
$\mathrm{M}$ & 0.0 & 0.0 & 0.0 & $1.22(4)$ \\
$\mathrm{A}$ & $0.2950(2)$ & $0.2950(2)$ & 0.0 & $1.19(3)$ \\
& & & & \\
$\alpha$-PbO 2 -Type (X-ray) & & & & \\
$\mathrm{M}$ & 0.0 & $0.1749(2)$ & 0.25 & $1.0(2)$ \\
$\mathrm{A}$ & $0.26944(96)$ & $0.3864(7)$ & $0.4201(9)$ & $0.4(1)$ \\
\hline
\end{tabular}

Refined site occupancies for the rutile-like phase

$\mathrm{M}$ occupancy $\mathrm{Nb}=0.71(1) \mathrm{Ga}=0.29(1)$ determined from refinement using the $\mathrm{x}$-ray data

A occupancy $\mathrm{O}=0.856(3) \quad \mathrm{N}=0.144$ (3) determined from refinement using the neutron data (see text) 
Table 4. Selected bond distances of oxynitride phases.

\begin{tabular}{|c|c|c|}
\hline Rutile & & \\
\hline M-A & $1.972(2)$ & $\mathrm{x} 4$ \\
\hline & $2.0372(8)$ & $\mathrm{x} 2$ \\
\hline M-M & $3.01372(5)$ & \\
\hline$\alpha-\mathrm{PbC}$ & & \\
\hline M-A & $1.918(4)$ & $\mathrm{x} 2$ \\
\hline & $1.989(4)$ & $x 2$ \\
\hline & $2.113(4)$ & $\mathrm{x} 2$ \\
\hline M-M & $3.166(1)$ & \\
\hline
\end{tabular}




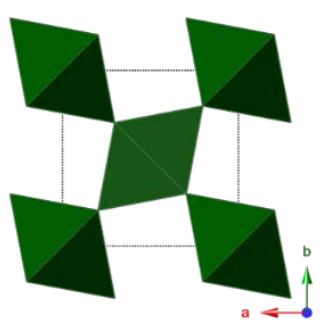

[001]

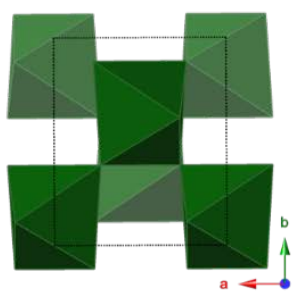

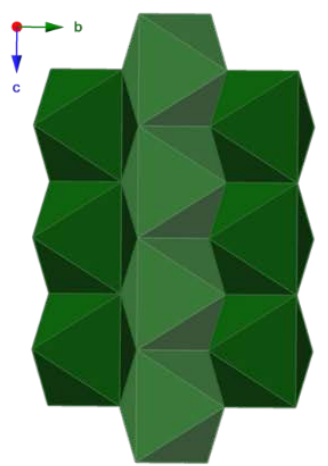

[100]

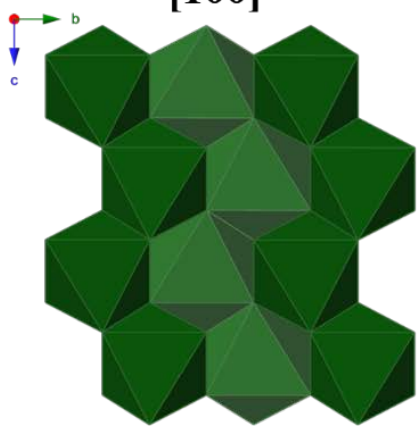

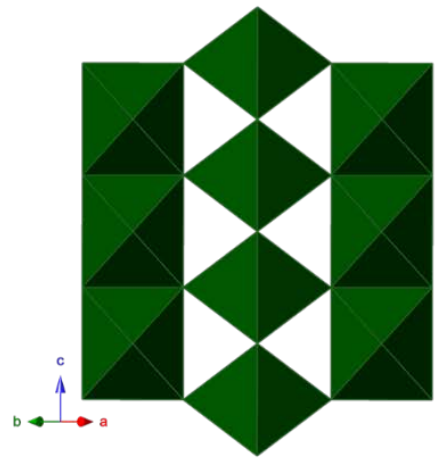

[110]

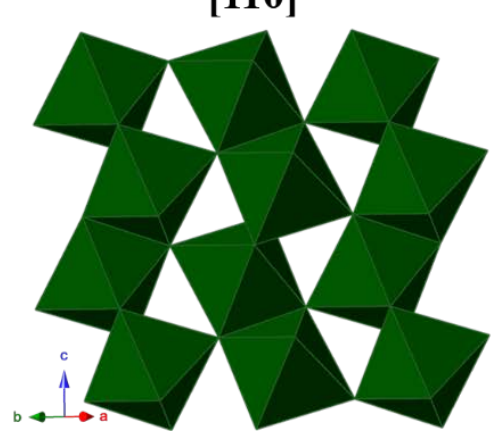

Figure 10. Crystal structure of rutile type (top) and $\alpha-\mathrm{PbO}_{2}$ type oxynitride phase (bottom) in polyhedral representation.

\section{Optical Properties of Rutile Type Oxynitride}

The optical properties of the rutile-structured oxynitride were evaluated using UV-VIS-NIR diffuse reflectance to determine whether the band gap was suitable for water splitting photocatalysis. Relative absorbance $\left(\alpha_{\mathrm{KM}}\right)$ was generated using a Kubelka-Munk transform and was fit using the same band gap functional fitting methods used to study the optical properties of $(\mathrm{GaN})_{1-\mathrm{x}}(\mathrm{ZnO})_{\mathrm{x}}$ nanorods and nanocrystalline gallium oxynitride spinel. ${ }^{63,}{ }^{64}$ The optical fitting revealed a contribution from a direct band gap of $0.84 \mathrm{eV}$ as well as an indirect band gap of 0.51 eV (Figure 11).

The optical data and band gaps are consistent with the black color of the powder as it absorbs through the visible range. The short band gap is unexpected as the respective oxide, $\mathrm{GaNbO}_{4}$, is 
a wide band-gap semiconductor. ${ }^{65,66}$ However, a HPHT reaction of $\mathrm{Ga}_{2} \mathrm{O}_{3}$ and $\mathrm{Nb}_{2} \mathrm{O}_{5}$ at identical synthesis conditions $\left(1 \mathrm{GPa}, 1000^{\circ} \mathrm{C}\right)$ produced a black powder of wolframite type $\mathrm{GaNbO}_{4}$ (Figure S2).The color in both the HPHT oxide and oxynitride is likely due to reduction of $\mathrm{Nb}^{5+}$ at the surface due to thermodynamically reducing conditions imposed by the graphite furnace. ${ }^{67}$ Such a surface reduction occurs when rutile, $\mathrm{TiO}_{2}\left(\mathrm{Ti}^{4+}\right.$ to $\left.\mathrm{Ti}^{3+}\right)$, is heated under reducing atmospheres. ${ }^{68}$ Synthesis under a less reducing atmosphere or post synthesis oxidative treatment could change the color and perceived optical band gap. Unfortunately, in the as synthesized state, the rutile type $\mathrm{Nb}_{1.412} \mathrm{Ga}_{0.583} \mathrm{O}_{3.412} \mathrm{~N}_{0.588}$ is not suitable for photocatalytic water splitting.

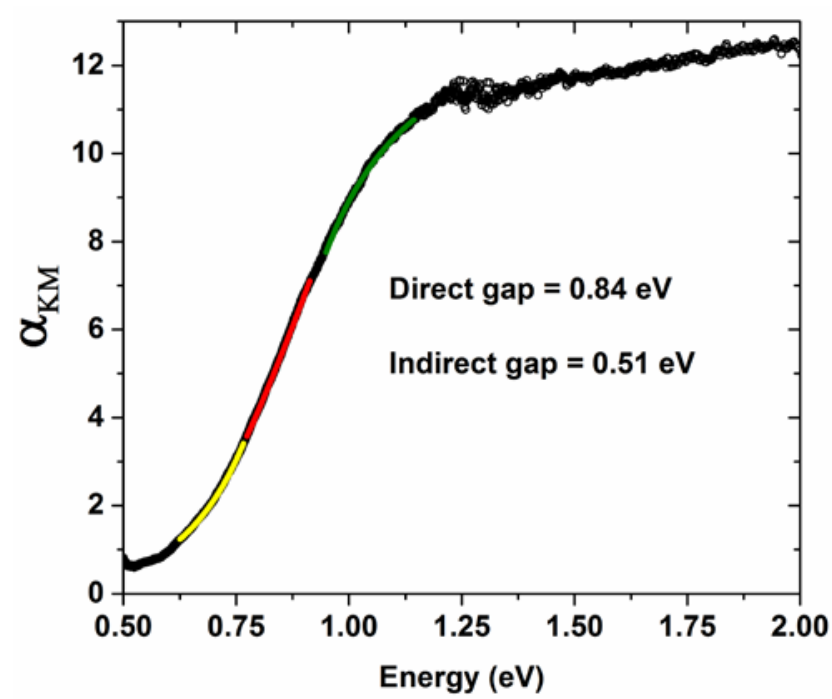

Figure 11. Kubelka-Munk absorption of the rutile type phase synthesized at $1 \mathrm{GPa}-1000^{\circ} \mathrm{C}$. The absorbance regions are modeled showing the direct band gap (green line), indirect band gap (red line), and the Urbach tail (yellow line).

\section{Conclusions}


We have demonstrated the successful use of combinatory techniques that can be used to speed up and optimize the discovery of compounds at high-pressure. While being used in a low resolution capacity, USPEX successfully guided the synthetic efforts acting as a reaction indicator of different compositions. While the predicted $\mathrm{GaNb}_{2} \mathrm{O}_{5} \mathrm{~N}$ oxynitride in the $\mathrm{GaN}-$ $\mathrm{Nb}_{2} \mathrm{O}_{5}$ system was not formed, the in situ EDXRD investigation mapped out the P-T reaction space in the course of a single day, leading to the discovery of two different $\mathrm{Nb}_{2} \mathrm{O}_{5}(\mathrm{GaN})_{0.83}$ phases having rutile and $\alpha-\mathrm{PbO}_{2}$ structures. Structural studies found the novel oxynitride phases have positional disorder amongst both the cations and the anions. The incorporation of positional disorder is currently not practical with state of the art crystal structure prediction algorithms. However, while the predicted structures may not match experimental results in the current implementation of USPEX, the variable-composition calculations offer insights into the chemistry of the system and can be used to direct synthetic efforts with $0 \mathrm{~K}$ calculations. To increase the likelihood of success in oxynitride prediction, future directions will need to incorporate/account for disorder to better evaluate oxynitride systems.

\section{ASSOCIATED CONTENT}

Experimental details on the behavior of GaN at conditions of high pressure and high temperature (HPHT), the synthesis of $\mathrm{NbGaO}_{4}$ at HPHT, and details of the structure analysis obtained through refinements using $\mathrm{x}$-ray and neutron diffraction data.(PDF)

This material is available free of charge via the Internet at http://pubs.acs.org.

\section{Corresponding Author}

*Corresponding author: john.parise@stonybrook.edu 


\section{Acknowledgments}

The theoretical calculations, HPHT synthesis, and analysis of the synchrotron, neutron, and optical data by W.R.W., A.R.O., G.Q., and H.A.N.D. was supported by the National Science Foundation under its materials Genome Initiative, Grant DMR-1231586. The use of the National Synchrotron Light Source, Brookhaven National Laboratory, was supported by the U.S. Department of Energy, Office of Science, Office of Basic Energy Sciences, under Contract No. DE-AC02-98CH10886. Use of the X17B2 beamline was supported by COMPRES, the Consortium for Materials Properties Research in Earth Sciences under NSF Cooperative Agreement EAR 10-43050 and by the Mineral Physics Institute, Stony Brook University. The collection of high-resolution X-ray diffraction patterns at the Advanced Photon Source was supported by the U.S. Department of Energy, Office of Science, Office of Basic Energy Sciences, under Contract No. DE-AC02-06CH11357. The neutron scattering measurements at POWGEN were supported by the Office of Basic Energy Sciences, U.S. Department of Energy, at the Spallation Neutron Source, Oak Ridge National Laboratory under contract DE-AC0500OR22725 with UT Battelle. 


\section{References}

(1) Demazeau, G.; Huppertz, H.; Alonso, J. A.; Pöttgen, R.; Moran, E.; Attfield, J. P., Z. Naturforsch., B: Chem. Sci. 2006, 61, 1457 - 1470.

(2) Range, K.-J., Chem. Unserer. Zeit. 1976, 10, 180-188.

(3) Huppertz, H., Chem. Commun. 2011, 47, 131-140.

(4) Badding, J. V.; Meng, J. F.; Polvani, D. A., Chem. Mater. 1998, 10, 2889-2894.

(5) Gregoryanz, E.; Sanloup, C.; Somayazulu, M.; Badro, J.; Fiquet, G.; Mao, H.-k.; Hemley, R. J., Nature Mater. 2004, 3, 294-297.

(6) Zhang, W.; Oganov, A. R.; Goncharov, A. F.; Zhu, Q.; Boulfelfel, S. E.; Lyakhov, A. O.; Stavrou, E.; Somayazulu, M.; Prakapenka, V. B.; Konopkova, Z., Science 2013, 342, 1502-1505.

(7) Lazicki, A.; Goncharov, A. F.; Struzhkin, V. V.; Cohen, R. E.; Liu, Z.; Gregoryanz, E.; Guillaume, C.; Mao, H. K.; Hemley, R. J., Proc. Natl. Acad. Sci. U.S.A. 2009, 106, 6525-6528.

(8) Eremets, M. I.; Trojan, I. A., JETP Lett. 2009, 89, 174-179.

(9) Oganov, A. R.; Ma, Y.; Lyakhov, A. O.; Valle, M.; Gatti, C., Rev. Mineral. Geochem. 2010, 71, 271-298.

(10) Oganov, A. R.; Glass, C. W., J. Phys.: Condens. Matter 2008, 20, 064210.

(11) Oganov, A. R.; Chen, J.; Gatti, C.; Ma, Y.; Ma, Y.; Glass, C. W.; Liu, Z.; Yu, T.; Kurakevych, O. O.; Solozhenko, V. L., Nature 2009, 457, 863-867.

(12) Ma, Y.; Eremets, M.; Oganov, A. R.; Xie, Y.; Trojan, I.; Medvedev, S.; Lyakhov, A. O.; Valle, M.; Prakapenka, V., Nature 2009, 458, 182-185.

(13) Solozhenko, V. L.; Solozhenko, E. G.; Zinin, P. V.; Ming, L. C.; Chen, J.; Parise, J. B., J. Phys. Chem. Solids 2003, 64, 1265-1270.

(14) Maddox, J., Nature 1988, 335, 201-201.

(15) DiSalvo, F. J., Science 1990, 247, 649-655.

(16) Glass, C. W.; Oganov, A. R.; Hansen, N., Comput. Phys. Commun. 2006, 175, 713-720.

(17) Hautier, G.; Fischer, C.; Ehrlacher, V.; Jain, A.; Ceder, G., Inorg. Chem. 2011, 50, 656663.

(18) Wu, Y.; Lazic, P.; Hautier, G.; Persson, K.; Ceder, G., Energy Environ. Sci. 2013, 6, 157168.

(19) Curtarolo, S.; Morgan, D.; Persson, K.; Rodgers, J.; Ceder, G., Phys. Rev. Lett. 2003, 91, 135503.

(20) Demazeau, G., Z. Naturforsch., B: Chem. Sci. 2006, 61, 799-807.

(21) Fuertes, A., Dalton Trans. 2010, 39, 5942-5948.

(22) Maeda, K.; Domen, K., J. Phys. Chem. C 2007, 111, 7851-7861.

(23) Maeda, K.; Domen, K., MRS Bull. 2011, 36, 25-31.

(24) Maeda, K.; Teramura, K.; Domen, K., J Catal. 2008, 254, 198-204.

(25) Tassel, C.; Kuno, Y.; Goto, Y.; Yamamoto, T.; Brown, C. M.; Hester, J.; Fujita, K.; Higashi, M.; Abe, R.; Tanaka, K.; Kobayashi, Y.; Kageyama, H., Angew. Chem. Int. Ed. 2015, $54,516-521$.

(26) Troyanchuk, I. O.; Kasper, N. V.; Mantytskaya, O. S.; Shapovalova, E. F., Mater. Res. Bull. 1995, 30, 421-425.

(27) Yang, M.; Rodgers, J. A.; Middler, L. C.; Oró-Solé, J.; Jorge, A. B. n.; Fuertes, A.; Attfield, J. P., Inorg. Chem. 2009, 48, 11498-11500.

(28) Soignard, E.; Machon, D.; McMillan, P. F.; Dong, J.; Xu, B.; Leinenweber, K., Chem. Mater. 2005, 17, 5465-5472. 
(29) Kinski, I.; Miehe, G.; Heymann, G.; Theissmann, R.; Riedel, R.; Huppertz, H., Z. Naturforsch., B: Chem. Sci. 2005, 60, 831-836.

(30) Huppertz, H.; Hering, S. A.; Zvoriste, C. E.; Lauterbach, S.; Oeckler, O.; Riedel, R.; Kinski, I., Chem. Mater. 2009, 21, 2101-2107.

(31) Hering, S. A.; Zvoriste, C. E.; Riedel, R.; Kinski, I.; Huppertz, H., Z. Naturforsch., B: Chem. Sci. 2009, 64, 1115-1126.

(32) Chen, H.; Wang, L.; Bai, J.; Hanson, J. C.; Warren, J. B.; Muckerman, J. T.; Fujita, E.; Rodriguez, J. A., J. Phys. Chem. C 2010, 114, 1809-1814.

(33) Haines, J.; Chateau, C.; Léger, J. M.; Le Sauze, A.; Diot, N.; Marchand, R.; Hull, S., Acta Crystallogr., Sect. B: Struct. Sci. 1999, 55, 677-682.

(34) Baumann, D.; Sedlmaier, S. J.; Schnick, W., Angew. Chem. Int. Ed. 2012, 51, 4707-4709.

(35) Li, Q.; Ma, Y.; Oganov, A. R.; Wang, H.; Wang, H.; Xu, Y.; Cui, T.; Mao, H.-K.; Zou, G., Phys. Rev. Lett. 2009, 102, 175506.

(36) Oganov, A. R.; Ma, Y.; Xu, Y.; Errea, I.; Bergara, A.; Lyakhov, A. O., Proc. Natl. Acad. Sci. U.S.A. 2010, 107, 7646-7651.

(37) Zhou, X.-F.; Oganov, A. R.; Qian, G.-R.; Zhu, Q., Phys. Rev. Lett. 2012, 109, 245503.

(38) Bazhanova, Z. G.; Oganov, A. R.; Gianola, O., Phys. Usp. 2012, 55, 489-497.

(39) Zeng, Q.; Peng, J.; Oganov, A. R.; Zhu, Q.; Xie, C.; Zhang, X.; Dong, D.; Zhang, L.; Cheng, L., Phys. Rev. B 2013, 88, 214107.

(40) Zhu, Q.; Jung, D. Y.; Oganov, A. R.; Glass, C. W.; Gatti, C.; Lyakhov, A. O., Nature Chem. 2012, 5, 61-65.

(41) Zhu, Q.; Oganov, A. R.; Lyakhov, A. O., Phys. Chem. Chem. Phys. 2013, 15, 7696.

(42) Cheng, X.; Zhang, W.; Chen, X.-Q.; Niu, H.; Liu, P.; Du, K.; Liu, G.; Li, D.; Cheng, H.M.; Ye, H.; Li, Y., Appl. Phys. Lett. 2013, 103, 171903.

(43) Cheng, X.-Y.; Chen, X.-Q.; Li, D.-Z.; Li, Y.-Y., Acta Crystallogr., Sect. C: Cryst. Struct. Commun. 2014, 70, 85-103.

(44) Zeng, Q.; Oganov, A. R.; Lyakhov, A. O.; Xie, C.; Zhang, X.; Zhang, J.; Zhu, Q.; Wei, B.; Grigorenko, I.; Zhang, L.; Cheng, L., Acta Crystallogr., Sect. C: Cryst. Struct. Commun. 2014, 70, 76-84.

(45) Yang, M.; Oró-Solé, J.; Rodgers, J. A.; Jorge, A. B.; Fuertes, A.; Attfield, J. P., Nature Chem. 2010, 3, 47-52.

(46) Attfield, J. P., Cryst. Growth Des. 2013, 13, 4623-4629.

(47) Clark, L.; Oró-Solé, J.; Knight, K. S.; Fuertes, A.; Attfield, J. P., Chem. Mater. 2013, 25, 5004-5011.

(48) Oró-Solé, J.; Clark, L.; Bonin, W.; Attfield, J. P.; Fuertes, A., Chem. Commun. 2013, 49, 2430 .

(49) Oró-Solé, J.; Clark, L.; Kumar, N.; Bonin, W.; Sundaresan, A.; Attfield, J. P.; Rao, C. N. R.; Fuertes, A., J. Mater. Chem. A 2014, 2, 2212.

(50) Bischoff, A.; Grund, T.; Jording, T.; Heying, B.; Hoffmann, R. D.; Rodewald, U. C.; Pottgen, R., Z. Naturforsch., B: Chem. Sci. 2005, 60, 1231-1234.

(51) Srinivasa, S. R.; Cartz, L.; Jorgensen, J. D.; Worlton, T. G.; Beyerlein, R. A.; Billy, M., J. Appl. Crystallog. 1977, 10, 167-171.

(52) Yashima, M.; Lee, Y.; Domen, K., Chem. Mater. 2007, 19, 588-593.

(53) Oganov, A. R.; Glass, C. W., J. Chem. Phys. 2006, 124, 244704.

(54) Oganov, A. R.; Lyakhov, A. O.; Valle, M., Acc. Chem. Res. 2011, 44, 227-237. 
(55) Lyakhov, A. O.; Oganov, A. R.; Stokes, H. T.; Zhu, Q., Comput. Phys. Commun. 2013, 184, 1172-1182.

(56) Blöchl, P. E., Phys. Rev. B 1994, 50, 17953-17979.

(57) Kresse, G.; Furthmüller, J., Phys. Rev. B 1996, 54, 11169-11186.

(58) Perdew, J. P.; Burke, K.; Ernzerhof, M., Phys. Rev. Lett. 1996, 77, 3865-3868.

(59) Troullier, N.; Martins, J. L., Phys. Rev. B 1991, 43, 1993-2006.

(60) Larson, A. C.; Von Dreele, R. B. Report LAUR 86-748; Los Alamos National Laboratory, New Mexico, USA 1986.

(61) Toby, B. H., J. Appl. Crystallog. 2001, 34, 210-213.

(62) Shannon, R. D., Acta Crystallogr., Sect. A: Found. Crystallogr. 1976, 32, 751-767.

(63) Reinert, A. A.; Payne, C.; Wang, L.; Ciston, J.; Zhu, Y.; Khalifah, P. G., Inorg. Chem. 2013, 52, 8389-8398.

(64) Dharmagunawardhane, H. A. N.; Woerner, W. R.; Wu, Q.; Huang, H.; Chen, X.; Orlov, A.; Khalifah, P. G.; Parise, J. B., J. Mater. Chem. A 2014, 2, 19247-19252.

(65) Blasse, G.; Buth, A. H.; Tamura, S., J. Solid State Chem. 1981, 37, 264-266.

(66) Devi, S.; Kelkar, S.; Kashid, V.; Salunke, H. G.; Gupta, N. M., RSC Adv. 2013, 3, 16817.

(67) Whitaker, M. L.; Nekvasil, H.; Lindsley, D. H.; Difrancesco, N. J., J Petrol. 2007, 48, 365-393.

(68) Khomenko, V. M.; Langer, K.; Rager, H.; Fett, A., Phys. Chem. Mineral. 1998, 25, 338346. 


\section{For Table of Contents Only}

Two new oxynitride phases resulting from the high-pressure high-temperature reaction between $\mathrm{GaN}$ and $\mathrm{Nb}_{2} \mathrm{O}_{5}$ have been identified. Reaction conditions and molar ratios of reagents where rapidly identified via a combination of USPEX for crystal structure prediction theory and in situ synchrotron-based X-ray scattering. We propose that this is a powerful method to systematically expedite the search for new oxynitride photocatalysts for water splitting and other functional materials.

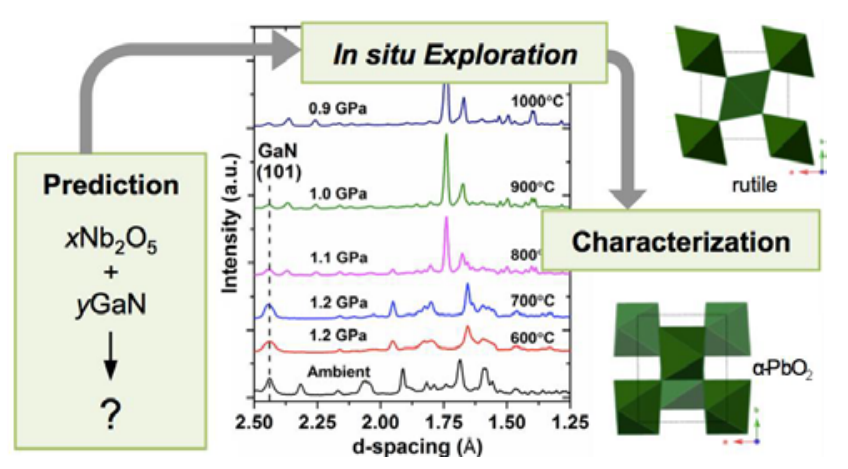

